\title{
DESENVOLVIMENTO DE UMA NANOARQUITETURA DE DNA BASEADA EM POLIPIRROL, NANOESTRUTURAS DE OURO E CISTEAMINA PARA O DIAGNÓSTICO DE HPV DE ALTO RISCO ONCOGÊNICO
}

\author{
K. Y. P. S. AVELINO ${ }^{1,2}$, L. S. OLIVEIRA ${ }^{1}$, N. LUCENA-SILVA ${ }^{3}$, C. A. S. ANDRADE ${ }^{1,2}$ \\ e M. D. L. OLIVEIRA ${ }^{1,2}$ \\ ${ }^{1}$ Universidade Federal de Pernambuco, Centro de Biociências, Departamento de Bioquímica, \\ Laboratório de Biodispositivos Nanoestruturados, Recife/PE, Brasil \\ ${ }^{2}$ Universidade Federal de Pernambuco, Centro de Biociências, Programa de Pós-Graduação \\ em Inovação Terapêutica, Recife/PE, Brasil \\ ${ }^{3}$ Centro de Pesquisas Aggeu Magalhães, Fundação Oswaldo Cruz, Recife/PE, Brasil \\ E-mail para contato: kareniasmim@hotmail.com
}

\begin{abstract}
RESUMO - Estudos clínicos e epidemiológicos demonstram que a infecção por papilomavírus humano (HPV) de alto risco oncogênico pode levar ao desenvolvimento de câncer cervical em aproximadamente $100 \%$ dos casos. Entretanto, as técnicas moleculares disponíveis para a pesquisa de HPV apresentam obstáculos que limitam seu amplo uso em áreas hospitalares e laboratoriais. Diante desta problemática acerca do diagnóstico clínico de HPV, o presente estudo possui como principal objetivo construir uma nanoarquitetura de DNA baseada em polipirrol (PPY), nanoestruturas de ouro (AuNs) e cisteamina (Cys) para a deteç̧ão eletroquímica do HPV tipo 16.0 desenvolvimento da nanoarquitetura de DNA foi fundamentado em um processo de estruturação molecular. A caracterização de cada etapa de montagem do sistema e sua bioatividade foram realizados através das técnicas de voltametria cíclica (VC) e espectroscopia de impedância eletroquímica (EIE). As análises eletroquímicas demonstraram que após a exposição da nanoarquitetura de DNA às amostras de plasmídeos contendo o gene L1 do HPV16, ocorreram a diminuição das correntes amperométricas e o aumento da resistência à transferência de carga $\left(R_{C T}\right)$, indicando a capacidade de reconhecimento bioespecífico do dispositivo sensor. Portanto, conclui-se que uma nanoarquitetura de DNA foi construída com sucesso para a detecção ultrassensivel do HPV16 (limite de detecção de $1 \mathrm{fg} / \mu \mathrm{L}$ ), sendo considerada uma ferramenta promissora para o diagnóstico clínico de papilomavírus.
\end{abstract}

Palavras-chave: Biossensor. Impedância eletroquímica. Papiloma vírus. Voltametria cíclica.

ABSTRACT - Clinical and epidemiological studies have shown that infection with high-risk oncogenic human papillomavirus (HPV) can lead to the 
development of cervical cancer in approximately $100 \%$ of cases. However, the molecular techniques available for HPV screening present obstacles that limit its wide use in hospital and laboratory areas. Faced with this problematic about the clinical diagnosis of HPV, the present study has as main objective to construct a $D N A$ nanoarchitecture based on polypyrrole (PPY), gold nanostructures (AuNs) and cysteamine (Cys) for the electrochemical detection of HPV type 16. The development of the DNA nanoarchitecture was based on a molecular structuring process. The characterization of each stage of system assembly and its bioactivity were performed through the techniques of cyclic voltammetry $(\mathrm{CV})$ and electrochemical impedance spectroscopy (EIS). The electrochemical analyzes demonstrated that after the exposure of the DNA nanoarchitecture to the plasmid samples containing the HPV16 L1 gene, occurred a decrease of amperometric current and increased charge transfer resistance $\left(R_{C T}\right)$, indicating the biospecific recognition capability of the sensor device. Therefore, it is concluded that a DNA nanoarchitecture was successfully constructed for the ultrasensitive detection of HPVI6 (detection limit of $1 \mathrm{fg} / \mu \mathrm{L}$ ), being considered a promising tool for the clinical diagnosis of papillomavirus.

Keywords: Biosensor. Cyclic voltammetry. Electrochemical impedance. Papilloma virus.

\section{INTRODUÇÃO}

O HPV é um vírus de cadeia dupla de DNA não envelopado responsável por infecções nas mucosas e no epitélio anogenital (HUTTER; DECKER, 2016). Este patógeno apresenta alta incidência e prevalência entre jovens e adultos, sendo o vírus mais comum transmitido sexualmente (CIVIT; FRAGOSO; O'SULLIVAN, 2010). Atualmente, são conhecidos mais de 200 genótipos de HPV subdivididos de acordo com o seu potencial oncogênico em tipos de baixo risco (HPV6, 11, 40, 42, 43, 44, 53, 54, 61, 72, 73 e 81) associados ao aparecimento de verrugas genitais e tipos de alto risco (HPV16, 18, 31, 33, 35, 39, 45, 51, 52, 56, 58, 59 e 68) responsáveis por alterações citogenéticas que levam ao desenvolvimento de cânceres, como o câncer cervical, peniano, vaginal, vulvar e anal (CIVIT et al., 2012). Ademais, estudos epidemiológicos mostram que aproximadamente $100 \%$ dos casos de carcinoma cervical invasivo em todo o mundo estão correlacionados com infecções por HPV tipo 16 e 18 (CAMPOS-FERREIRA et al., 2013; HUANG et al., 2015).

A identificação do tipo de HPV em amostras clínicas possibilita um melhor prognóstico para o paciente, um diagnóstico de câncer em estágio inicial e a implementação de estratégias terapêuticas dirigidas para a obtenção de resultados mais satisfatórios. Além disso, permite o rastreamento de genótipos virais mais frequentes em uma população (HUTTER; DECKER, 2016). As principais técnicas moleculares utilizadas para a pesquisa de HPV compreendem a reação em cadeia da polimerase quantitativa em tempo real (RT-qPCR) e os ensaios de captura híbrida (CIVIT et al., 2012; HUANG et al., 2015). Apesar de serem específicos, estes métodos apresentam alguns obstáculos que limitam seu amplo uso em áreas hospitalares e laboratoriais, como os altos custos para a aquisição de equipamentos e protocolos experimentais complexos e demorados (CAMPOS-FERREIRA et al., 2013; URREGO et al., 2015). Logo, o desenvolvimento de ensaios moleculares para a detecção de HPV com elevada acurácia e performance bioanalítica é de grande interesse para a promoção da saúde de pacientes infectados (FRÍAS et al., 2015). 
Ao longo dos anos, os avanços da nanociência e o desenvolvimento biotecnológico possibilitaram a fabricação de novos dispositivos eletrônicos, como os biossensores. A estratégia funcional destes dispositivos fundamenta-se na especificidade de moléculas biológicas e na capacidade analítica de métodos de transdução de sinal (FRÍAS et al., 2015). Dentre os inúmeros tipos de biossensores, destacam-se os biossensores de DNA eletroquímicos por apresentarem estabilidade em condições ambientais adversas e elevada especificidade (SASSOLAS; LECA-BOUVIER; BLUM, 2008). Estes sensores são baseados na imobilização de segmentos de ácidos nucléicos sobre a superfície de um transdutor eletroquímico. Através de mudanças nas propriedades eletroquímicas do sistema decorrentes da hibridação entre um fragmento de cadeia simples de DNA e a cadeia complementar, é possível obter informações analíticas qualitativas ou quantitativas, específicas e seletivas (COSTA et al., 2014). Os biossensores de DNA apresentam amplo potencial de aplicabilidade para o diagnóstico clínico, pois, são métodos de detecção ultrassensíveis que permitem uma análise em tempo real de alvos moleculares a um baixo custo e requerem pequenos volumes de amostras. Em adição, a instrumentação é simples com a possibilidade de miniaturização, portabilidade e automação (ROSARIO; MUTHARASAN, 2014).

O desafio para a construção de biossensores consiste em preservar a atividade biológica da biomolécula após sua imobilização sobre superfícies transdutoras. Por esta razão, a associação de materiais nanométricos e polímeros condutores pode ser considerada uma alternativa inovadora para a construção de nanoarquiteturas biocompatíveis (ROVINA; SIDDIQUEE, 2016). Estas atuam como interfaces entre a biomolécula e o eletrodo, possibilitando uma ancoragem estável do receptor, sem perda de atividade biológica, o que determina um efetivo processo de biorreconhecimento.

Com a finalidade de contribuir para o desenvolvimento de novos ensaios de detecção para o papilomavírus, este trabalho científico possui o objetivo de construir uma nanoarquitetura de DNA baseada em PPy, AuNs e Cys para o diagnóstico ultrassensível do HPV16. O biodispositivo proposto poderá ser útil na identificação de infecções por HPV16, implementação de terapias adequadas e prevenção de câncer cervical, promovendo assim, a qualidade de vida da população.

\section{MATERIAIS E MÉTODOS}

\subsection{CONSTRUÇÃO DA NANOARQUITETURA DE DNA}

A nanoarquitetura de DNA foi construída sobre uma superfície de ouro que atuou como eletrodo de trabalho. Inicialmente, a área metálica foi submetida a um protocolo de limpeza para a remoção de partículas indesejadas. $\mathrm{O}$ eletrodo de trabalho foi polido em um disco de feltro com uma suspensão aquosa de alumina $\left(\mathrm{Al}_{2} \mathrm{O}_{3}\right)$ a uma granulação de $0,05 \mu \mathrm{m}$. Em seguida, foi enxaguado com água ultrapura, submetido a um banho de ultrassom durante 10 minutos e seco ao ar. A primeira etapa de montagem da nanoarquitetura de DNA consiste na eletropolimerização de pirrol. Para tal, o eletrodo de trabalho foi imerso em uma solução de ácido clorídrico $(\mathrm{HCl})$ a $0,5 \mathrm{M}$ contendo o monômero pirrol a uma concentração de $30 \mathrm{mM}$. Através da voltametria cíclica foram aplicados seis ciclos de polimerização em uma faixa de potencial de $-0,2 \mathrm{a}+0,7 \mathrm{~V}$ com uma velocidade de varredura de $100 \mathrm{mV} . \mathrm{s}^{-1}$. A segunda etapa compreende a síntese e deposição eletroquímica de AuNs sobre o filme de PPy. Utilizando uma solução de ácido tetracloroaúrico $\left(\mathrm{HAuCl}_{4}\right)$ a $0,25 \mathrm{mM}$, foram realizados dez ciclos voltamétricos com uma faixa de potencial de $+0,2$ a $-1 \mathrm{~V}$ e velocidade de varredura de 50 $\mathrm{mV} . \mathrm{s}^{-1}$ (LIN, 2015). A terceira etapa refere-se a quimissorção de moléculas de Cys sobre as 
AuNs. Este processo fundamenta-se em interações covalentes estabelecidas entre os grupos tióis (-SH) das moléculas de Cys e os átomos de ouro das nanoestruturas. Nesta etapa, foram adicionados $2 \mu \mathrm{L}$ de uma solução de Cys a $2 \mathrm{mg} / \mathrm{mL}$ (proporção volumétrica de etanol:água igual a 3:1) por 30 minutos. Após obter a plataforma nanoestruturada de PPy-AuNs-Cys foi realizada a quarta etapa que reporta-se a imobilização química de segmentos de oligonucleotídeos específicos para o reconhecimento do papilovírus (sondas de DNA). Primeiramente, $2 \mu \mathrm{L}$ de glutaraldeído a $0,5 \%$ foram adicionados sobre a plataforma nanoestruturada por 10 minutos. Posteriormente, $2 \mu \mathrm{L}$ de uma solução de oligonucleotídeos a $10 \mathrm{mM}$ foram acrescentados por 15 minutos para a construção da nanoarquitetura de DNA. O glutaraldeído atuou como um agente reticulante biofuncional, possibilitando a formação de bases de Schiff entre os grupos amino das moléculas de Cys e os grupos amino das sondas de DNA funcionalizadas. Por fim, a quinta etapa compreende o bloqueio dos sítios inespecíficos da nanoarquitetura de DNA com moléculas de albumina do soro bovino (BSA). Nesta etapa, foram acrescentados $2 \mu \mathrm{L}$ de uma solução de BSA a 1\% (pH 7,4) sobre a superfície do eletrodo modificado por 30 segundos. Logo, através deste processo metodológico, a nanoarquitetura de DNA baseada em PPy-AuNs-Cys foi desenvolvida.

\subsection{ESTUDO DE BIOATIVIDADE}

Com a finalidade de avaliar a especificidade e seletividade da nanoarquitetura de DNA, foram realizados estudos de hibridação com plasmídeos recombinantes contendo a sequência de nucleotídeos do gene L1 do HPV 16 (controle positivo) e plasmídeos recombinantes contendo uma sequência de nucleotídeos não-complementar à sonda de DNA (controle negativo). Em cada ensaio, a nanoarquitetura de DNA foi exposta a $2 \mu \mathrm{L}$ da amostra a ser testada por 15 minutos para promover o processo de biorreconhecimento. As diluições de todas as amostras biológicas foram preparadas com solução salina de tampão fosfato (PBS; $\mathrm{pH} 7,4)$ e mantidas congeladas.

\subsection{CARACTERIZAÇÃO ELETROQUÍMICA}

O processo de desenvolvimento da nanoarquitetura de DNA e sua bioatividade foram caracterizados através das técnicas de VC e EIE. As medidas voltamétricas e impedimétricas foram realizadas em um Potenciostato/Galvanostato Autolab PGSTAT 128N controlado por um computador através de um software de interfaceamento NOVA 1.11 (MetrohmAutolab, The Netherlands). Em adição, foi utilizada uma célula eletroquímica convencional de três eletrodos imersos em $20 \mathrm{~mL}$ de solução de ferro-ferricianeto de potássio $\mathrm{K}_{4}\left[\mathrm{Fe}(\mathrm{CN})_{6}\right] / \mathrm{K}_{3}\left[\mathrm{Fe}(\mathrm{CN})_{6}\right](1: 1)$ a $10 \mathrm{mM}$ em PBS $(\mathrm{pH} 7,4)$, atuando como sonda redox. O eletrodo de ouro modificado com a nanoarquitetura de DNA foi utilizado como eletrodo de trabalho, o eletrodo de $\mathrm{Ag} / \mathrm{AgCl}$ saturado com $\mathrm{KCl}$ a $3 \mathrm{M}$ e o eletrodo de platina foram usados, respectivamente, como eletrodo de referência e contra-referência. Os voltamogramas cíclicos foram obtidos em uma faixa de potencial de $-0,2 \mathrm{a}+0,7 \mathrm{~V}$ com velocidade de varredura de 50 $\mathrm{mV} . \mathrm{s}^{-1}$. Os espectros de impedância foram registrados em uma faixa de frequência de 100 $\mathrm{mHz}$ a $100 \mathrm{KHz}$ com um potencial de amplitude alternada de $10 \mathrm{mV}$. Todas as análises eletroquímicas foram realizadas em triplicatas, a temperatura ambiente e no interior de uma gaiola de Faraday. 


\section{RESULTADOS E DISCUSSÃO}

A figura 1 demonstra a caracterização eletroquímica das etapas de construção da nanoarquitetura de DNA. Verifica-se que o voltamograma cíclico para o eletrodo de ouro não modificado apresenta picos anódico e catódico bem definidos e uma taxa de transferência de carga reversível na presença da solução eletrolítica. Ao realizar a eletropolimerização do monômero pirrol sobre a superfície de ouro foi verificada um aumento da densidade de corrente e uma redução da resistência interfacial. É importante ressaltar que o processo de oxidação na superfície do eletrodo de trabalho leva à formação de um filme polimérico estável com elevada condutividade elétrica. Devido estas propriedades, o PPy é capaz de aumentar a sensibilidade e seletividade de sistemas bioanalíticos (GERARD; CHAUBEY; MALHOTRA, 2002; MAHMOUDIAN, et al., 2011).

Verifica-se que após a eletrossíntese das AuNs houve um decréscimo da resposta amperométrica e um aumento da impedância interfacial. Este resultado está relacionado às condições de síntese eletroquímica e às propriedades do filme de PPy, sobre o qual as AuNs foram depositadas. Em razão do filme polimérico ser aderente à superfície de ouro e possuir uma fina espessura, espera-se que o PPy proporcione um maior número de sítios de nucleação para a formação de nanoestruturas. De acordo com Li e Shi (2005), essas características do filme polimérico conduz à fabricação de AuNs com dimensões nanométricas reduzidas, presentes em um estado de não-agregação, que ocasiona uma diminuição de sua condutividade e aumento da área superficial.

Ao realizar a quimissorção de moléculas de Cys sobre as AuNs pode-se observar uma maior resposta condutimétrica e uma maior taxa de transferência de elétrons. Sabe-se que a molécula de Cys possui grupos funcionais tiol e amino que direcionam a formação de ligações covalentes entre nanoestruturas metálicas e biomoléculas. Em especial, o grupo amino pode ser protonado, passando a apresentar carga elétrica positiva que atrai eletrólitos carregados negativamente, como o ferricianeto $\left[\mathrm{Fe}(\mathrm{CN})_{6}\right]^{3-}$ e ferrocianeto $\left[\mathrm{Fe}(\mathrm{CN})_{6}\right]^{4-}$. Este processo favorece a ocorrência de reações de oxidorredução em regiões adjacentes à superfície do eletrodo. Logo, constata-se que a Cys é um composto orgânico que atua como um espaçador molecular e contribui para o aumento da sensibilidade de sistemas eletroquímicos (WANG et al., 2016).

Em seguida, foi observado que a ancoragem das sondas de DNA sobre o eletrodo modificado com PPy-AuNs-Cys causou uma redução do sinal de corrente e um aumento do diâmetro do semicírculo de Cole-Cole. Este resultado está relacionado a uma baixa penetração do par redox no sistema sensor. Isto ocorre devido à repulsão eletrostática entre os grupos fosfato das sondas de DNA e as cargas negativas dos eletrólitos $\left[\mathrm{Fe}(\mathrm{CN})_{6}\right]^{3-} /\left[\mathrm{Fe}(\mathrm{CN})_{6}\right]^{4-}$, contribuindo assim, para o bloqueio do processo redox na dupla camada elétrica (AVELINO et al., 2016). Como presumido, o bloqueio dos sítios inespecíficos da nanoarquitetura de DNA com moléculas de BSA resultou em um decréscimo da medida voltamétrica e um aumento da resistividade. Portanto, através destas caracterizações físico-químicas, 7777777 foi possível comprovar a adequada montagem da nanoarquitetura de DNA. 
Figura 1 - Voltamogramas cíclicos (a) e espectros de impedância (b) para cada etapa de montagem da nanoarquitetura de DNA baseada em polipirrol (PPy), nanoestruturas de ouro (AuNs) e cisteamina (Cys).

a)

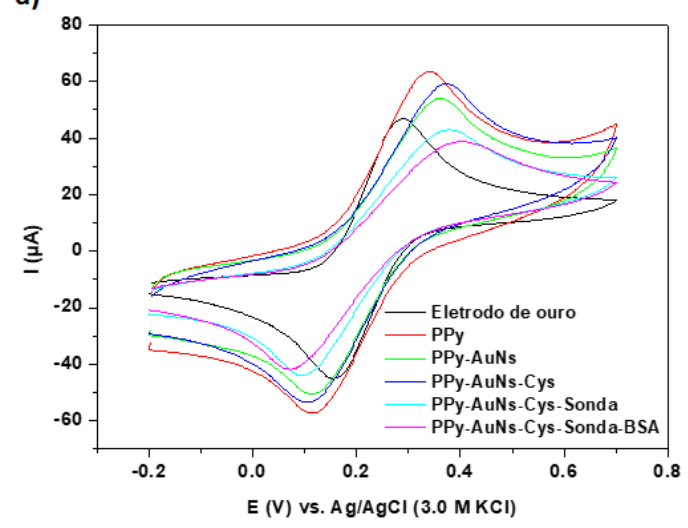

b)

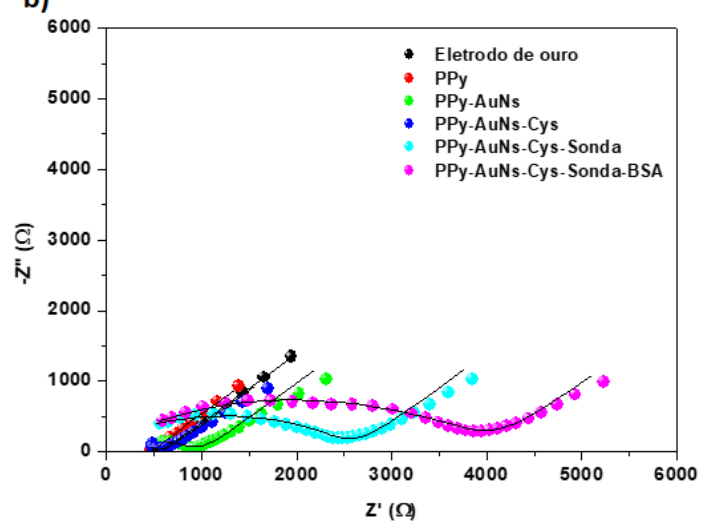

O desempenho analítico da nanoarquitetura de DNA foi avaliado através de sua interação com amostras de plasmídeos recombinantes contendo o gene L1 do HPV16. A Figura 2 ilustra a caracterização voltamétrica (Figura 2a) e impedimétrica (Figura 2b) da nanoarquitetura de DNA exposta às diferentes concentrações de amostras plasmidiais $(0,001$; 0,$\left.01 ; 0,1 ; 1 ; 10 ; 100 \mathrm{pg} \cdot \mu \mathrm{L}^{-1}\right)$. Após o processo de hibridação, pode-se observar uma diminuição nos valores das correntes de pico e uma redução das áreas voltamétricas, sendo estes decréscimos proporcionais ao aumento da concentração das amostras testadas (Figura 2a). Mudanças nas propriedades dielétricas do sistema e aumento nos valores de $R_{C T}$ também foram verificados, indicando a capacidade de reconhecimento bioespecífico do dispositivo desenvolvido (Figura 2b). Ademais, ensaios com sequências gênicas não complementares à sonda de DNA demonstraram a seletividade do bioeletrodo.

Segundo Avelino et al. (2016) o processo de hibridação é um evento de biorreconhecimento a nível da interface eletroquímica que ocasiona uma redução total da resposta amperométrica e um aumento da resposta impedimétrica. Sabe-se que o processo de hibridação entre a sonda e o DNA alvo resulta na formação de uma fita dupla de DNA (dsDNA) que possui propriedades não condutoras (BENVIDI et al., 2015). Logo, as respostas eletroquímicas obtidas após a exposição da nanoarquitetura de DNA ao gene L1 do HPV16 é devido a formação de híbridos dsDNA na superfície do sensor que ocasionam a redução do fluxo de elétrons para o transdutor.

Figura 2 - Caracterização voltamétrica (a) e impedimétrica (b) da nanoarquitetura de DNA exposta às amostras de plasmídeos recombinantes contendo o gene L1 do HPV16 em variáveis concentrações $\left(0,001 ; 0,01 ; 0,1 ; 1 ; 10 ; 100 \mathrm{pg} . \mu \mathrm{L}^{-1}\right)$.

a)

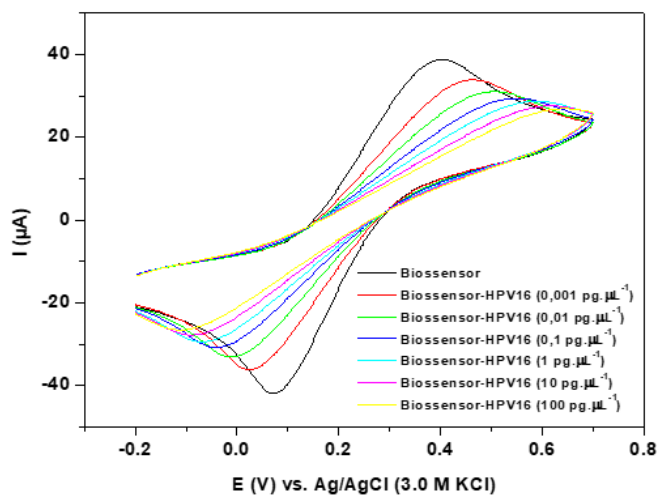

b)

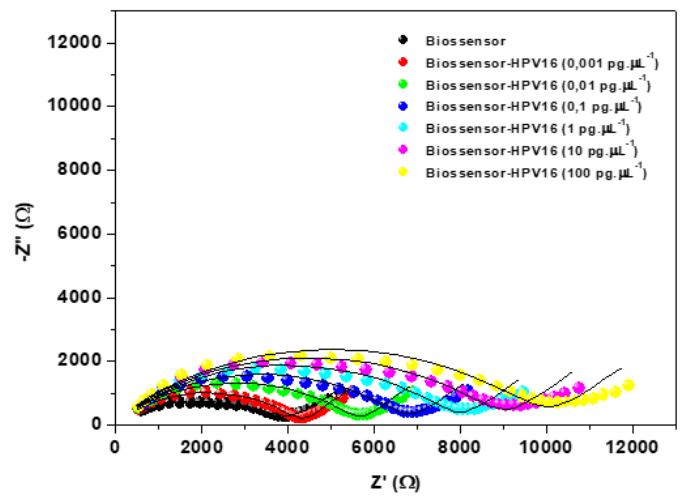




\section{CONCLUSÃO}

Uma nanoarquitetura de DNA foi construída de forma eficaz e reprodutível para a detecção ultrassensível de HPV16. Através da associação de distintos materiais (PPy, AuNs e Cys), obtive-se um sistema com propriedades singulares para o interfaceamento do reconhecimento biológico. O biodispositivo proposto é capaz de identificar o gene L1 do HPV16 em concentrações mínimas (limite de detecção de $1 \mathrm{fg} / \mu \mathrm{L}$ ). Além disto, apresenta rápido tempo de resposta, reprodutibilidade, especificidade e seletividade. Portanto, a nanoarquitetura de DNA pode ser considerada um instrumento com grande potencial para o diagnóstico molecular do papilomavírus, contribuindo para a identificação da infecção em estágio inicial e prevenção do câncer cervical.

\section{REFERÊNCIAS}

AVELINO, K. Y. P. S. et al. Attomolar electrochemical detection of the BCR/ABL fusion gene based on an amplifying self-signal metal nanoparticle-conducting polymer hybrid composite. Colloids and Surfaces B: Biointerfaces, v. 148, p. 576-584, 2016.

BENVIDI, A. et al. Ultrasensitive DNA sensor based on gold nanoparticles/reduced graphene oxide/glassy carbon electrode. Analytical Biochemistry, v. 484, p. 24-30, 2015.

CAMPOS-FERREIRA, D. S. et al. Electrochemical DNA biosensor for human papillomavirus 16 detection in real samples. Analytica Chimica Acta, v. 804, p. 258- 263, 2013.

CIVIT et al. Electrochemical genosensor array for the simultaneous detection of multiple high-risk human papillomavirus sequences in clinical samples. Analytica Chimica Acta, v. 715, p. 93-98, 2012.

CIVIT, L.; FRAGOSO, A.; O'SULLIVAN, C. K. Electrochemical biosensor for the multiplexed detection of human papillomavirus genes. Biosensors and Bioelectronics, v. 26, p. 1684-1687, 2010.

COSTA, M. P. et al. Self-assembled monolayers of mercaptobenzoic acid and magnetite nanoparticles as an efficient support for development of tuberculosis genosensor. Journal of Colloid and Interface Science, v. 433, p. 141-148, 2014.

FRÍAS, I. A. M. et al. Trends in biosensors for HPV: identification and diagnosis. Journal of Sensors, v. 2015, p. 1-16, 2015.

GERARD, M.; CHAUBEY, A.; MALHOTRA, B. D. Application of conducting polymers to biosensors. Biosensors and bioelectronics, v. 17, n. 5, p. 345-359, 2002.

HUANG, H. et al. An ultrasensitive electrochemical DNA biosensor based on graphene/Au nanorod/polythionine for human papillomavirus DNA detection. Biosensors and Bioelectronics, v. 68, p. 442-446, 2015.

LI, Y.; SHI, G. Electrochemical growth of two-dimensional gold nanostructures on a thin polypyrrole film modified ITO electrode. The Journal of Physical Chemistry B, v. 109, n. 50, p. 23787-23793, 2005.

LIN, M. A dopamine electrochemical sensor based on gold nanoparticles/over-oxidized polypyrrole nanotube composite arrays. RSC Advances, v. 5, n. 13, p. 9848-9851, 2015.

MAHMOUDIAN, M. R. et al. Electrochemical characteristics of coated steel with poly (Nmethyl pyrrole) synthesized in presence of $\mathrm{ZnO}$ nanoparticles. Thin Solid Films, v. 520, n. 1, p. 258-265, 2011.

ROSARIO, R.; MUTHARASAN, R. Nucleic acid electrochemical and electromechanical 
biosensors: a review of techniques and developments. Reviews in Analytical Chemistry, v. 33, n. 4, p. 213-230, 2014.

ROVINA, K.; SIDDIQUEE, S. Electrochemical sensor based rapid determination of melamine using ionic liquid/zinc oxide nanoparticles/chitosan/gold electrode. Food Control, v. 59, p. 801-808, 2016.

SASSOLAS, A.; LECA-BOUVIER, B. D.; BLUM, L. J. DNA Biosensors and Microarrays. Chemical Reviews, v. 108, n.1, p. 109-139, 2008.

URREGO, L. F. et al. Biomicrosystem design and fabrication for the human papilloma virus 16 detection. Sensors and Actuators B: Chemical, v. 207, p. 97-104, 2015.

WANG, N. et al. Functionalized gold nanoparticles/reduced graphene oxide nanocomposites for ultrasensitive electrochemical sensing of mercury ions based on thymine-mercurythymine structure. Biosensors and Bioelectronics, v. 79, p. 320-326, 2016.

\section{AGRADECIMENTOS}

Ao CNPq, FINEP, FACEP, UFPE e Propesq pelo apoio financeiro e incentivo à pesquisa. 